\title{
A new codefor life
}

\author{
Expansion of thegenetic codeand artificial assembly of functional genomes are raising important \\ questions about ethics and safety
}

0 ne of the apparent certitudes in the life sciences is the universality of the genetic code: four nucleotides specify 64 triplet codons to encode the 20 amino acids from which all organisms synthesize proteins. But this certainty is no longer guaranteed. Several research groups have succeeded in expanding the genetic code of both prokaryotic and eukaryotic organisms by adding non-natural amino acids. This may lead to the synthesis of proteins with novel biological, chemical and physical properties with significant consequences for biotechnology and medicine.

\section{... the ability to modify proteins specifically with custom-made amino acids holds tremendous potential for both basic and applied research}

The expansion of the genetic codenot to be confused with standard genetic engineering of proteins with naturally occurring amino acids-started about 15 years ago, when research groups led by Richard Chamberlin at the University of California (Irvine, USA) and Peter Schultz at the Scripps Research Institute (La Jolla, CA, USA) developed the 'amber suppression method' for incorporating non-natural amino acids into proteins (Fig 1). This method uses chemically aminoacylated amber suppressor tRNAs to introduce non-natural amino acids into large proteins in vitro and in microinjected cells. Since then, biologists have expanded their molecular toolbox with new strategies, such as the aminoacylation of tRNAs with non-natural amino acids based on the action of either ribozymes or appropriately mutated aminoacyl-tRNA synthetases, or by generating non-standard codons that contain four or five bases or include non-natural base pairs (Hohsaka \& Sisido, 2002; Wang \& Shult, 2002). These methods now make it feasible to encode artificial amino acids genetically and to insert them into proteins in vivo with high selectivity and fidelity. First applied to Escherichia coli (Wang et al, 2001), a modified in vivo protocol for the yeast Saccharomyces cerevisiae (Chin et al, 2003) has now introduced the possibility of expanding the genetic code of multicellular eukaryotes.

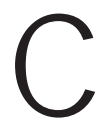
learly, the ability to modify proteins specifically with custom-made amino acids holds tremendous potential for both basic and applied research. The amino-acid outfit of E. coli has already been expanded with the creation of a new residue containing a keto group, the most versatile of the functional groups in organic chemistry but absent in the natural amino acids. This addition offers an adaptable 'reactive handle' to label proteins with hydrazide and hydroxylamine derivatives of sugars, spin labels, metal chelators, crosslinking agents, polyethers, fatty acids and toxins (Wang et al, 2003a). Similarly, the substitution of a tyrosine residue in green fluorescent protein with several tyrosine analogues has created mutant proteins with colour emissions ranging from blue to cyan to green and other new spectral properties (Wang et al, 2003b). "Such modifications can be used to probe protein structure and function, to generate proteins with enhanced catalytic or therapeutic properties, or for the development of bioassays using either immobilized or soluble proteins," wrote Schultz and his co-authors (Wang et al, 2003a), or "for the in vivo imaging of protein localization, protein movement and conformational changes in proteins at molecular resolution."

\section{Is therea particular reason why only 20 amino acids, and these particular 20, comprise the genetic code?}

But this technology may also help to answer some central questions about the evolution of life. "The origin of the genetic code, whether a 'frozen accident' or an expansion from a primordial code with fewer amino acids, remains an enigma," commented Lei Wang, the lead author on many of these studies (Wang, 2003). Is there a particular reason why only 20 amino acids, and these particular 20, comprise the genetic code? Why hasn't the code evolved further? Might additional amino acids lead to organisms with

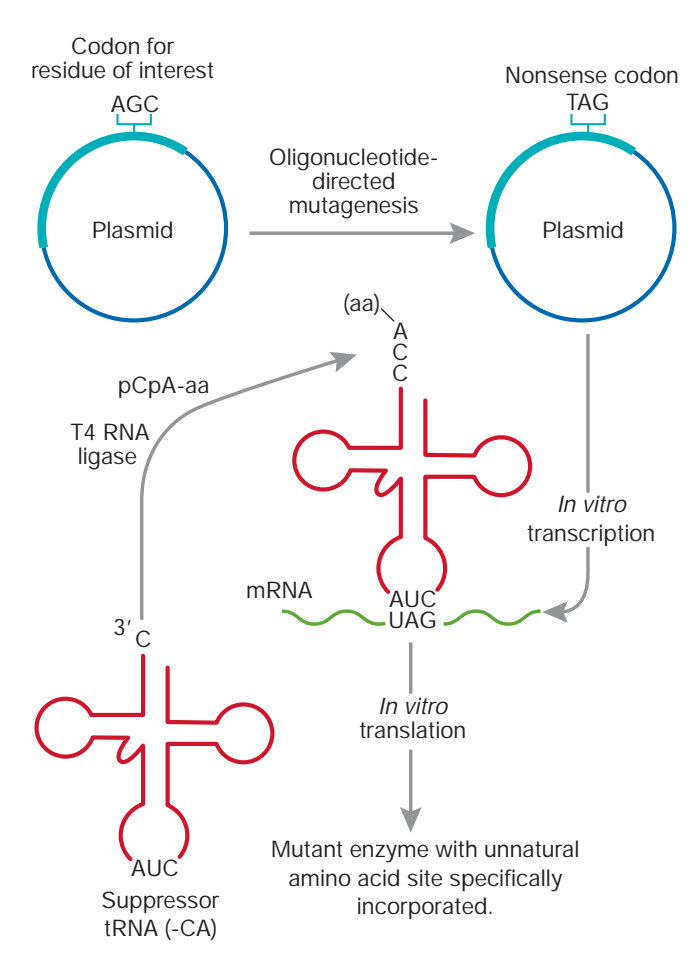

Fig1|Theamber suppression method to incorporate non-natural amino acids into proteins in vitro. Adapted from Noren et al (1989). 
enhanced function? To evaluate the evolutionary consequences of adding novel amino acids to the genetic repertoire, Shultz, Wang and colleagues have generated a completely autonomous E. coli that can biosynthesize an extra, non-standard amino acid from simple carbon sources and incorporate it into proteins, with no apparent toxic side effects ( $M$ ehl et al, 2003). "Directed evolution of such organisms under selective pressure is under way and may shed light on whether additional amino acids give an evolutionary advantage," said Wang.

$\mathrm{T}$ he move from creating new proteins to creating new life seems only a small step away. Indeed, the long-standing dream-or nightmare, depending on the point of view - of artificial life recently moved closer to reality. This research began in the mid-to-late 1990s at The Institute for Genomic Research (Rockville, MD, USA), the nonprofit research institute founded by Craig Venter in 1992. Venter and colleagues started the so-called 'minimal genome project' to identify the minimal genetic components necessary to sustain life. The research group, including Clyde Hutchinson, Claire Fraser and Hamilton Smith, chose Mycoplasma genitalium as a working model, because this bacterium has the smallest known cellular genome (580 kilobases, with 480 protein-coding genes and 37 genes for RNA species). Using a 'top-down' approach, the researchers eliminated nonessential genes, one by one, using global transposon mutagenesis to identify some 265350 protein-encoding genes that are essential for $M$. genitalium to live under laboratory conditions (Hutchinson et al, 1999). At a speech at the annual meeting of the American Association for the Advancement of Science (AAAS) in Anaheim (CA, USA), in 1999, Venter argued that the creation of man-made microorganisms from a cocktail of small molecules could reveal how life first evolved on Earth. Answering the question "W hat is life?" in genomic terms was only the first step towards engineering a cell with the capacity to self-replicate.

\section{The move from creating new proteins to creating new life seems only a small step away}

\section{"Synthetic genomics will become common place and will provide the potential for a vast array of new and complex chemistries altering our approaches to production of energy, pharmaceuticals, and textiles"}

Even the remote possibility that minimal genome research could lead to creating life "from scratch" was perfect fuel to add to the debates about the relevant ethical and safety problems. Venter anticipated his opponents' moves and deflected some of their criticism by commissioning an ethical review of the research by a team of experts led by Mildred Cho of Stanford University's Center for Biomedical Ethics (CA, USA). This independent panel reviewed the different implications of the research from religious and metaphysical issues to the thorny matter of intellectual property and patentability of synthesized genomes and organisms. After more than a year of work, the group's deliberations were published at the same time as the scientific minimal genome research (Cho et al, 1999). "Without prior discussion of ethical issues, the general public cannot develop a framework or common language to discuss acceptable uses of a new biomedical technology, or even whether it should be used at all," introduced Cho and colleagues. The main conclusion of such a "proactive identification and debate of the associated ethical issues" was that "the prospect of constructing minimal and new genomes does not violate any fundamental moral precepts or boundaries, but does raise questions that are essential to consider before the technology advances further"-questions such as how we frame ideas of life and our relationship to it, and what law and policy should do to ensure the new technological possibilities would benefit all. The panel also stressed that for this scientific approach to be ethically sustainable, scientists should continue to engage public discussion. "It might be considered a Godlike activity," Cho said about creating artificial organisms, "but I think our group has concluded that manipulating organisms has long been a part of human tradition."
W ith a green light flashing on the project thanks to the positive results of the self-invoked ethical scrutiny, Venter took the next step, creating a synthetic chromosome to test the viability of the minimal gene set hypothesis. In N ovember 2002, The Institute for Biological Energy Alternatives (IBEA), founded the same year by Venter to employ genomics to use microbes and plants as potential solutions to carbon sequestration and clean energy production, received a three-year US\$3 million grant from the US Department of Energy as part of the Department's "Genomes to Life" initiative to construct an artificial chromosome. "We believe that building a synthetic chromosome is an important step toward realizing these goals because we could potentially engineer an organism with the ideal qualities to begin to cope with our energy issues," said Venter, explaining the rationale behind founding the IBEA, and highlighting the potentials of genetic engineering powered by the minimalistic genome approach to produce biological fuels, such as hydrogen, in an environmentally sound fashion.

\section{... these advances can be used to answer central questions about basic biology, help the world to solve some of its environmental problems, provide improved tools to engineer useful plants and animals and treat lethal human diseases...}

Last year, the IBEA team announced the in vitro assembly of the whole genome of bacteriophage $\phi X 174$, starting from a pool of synthetic, commercially available oligonucleotides (Smith et al, 2003). Using polymerase cycle assembly (PCA)-a nonamplifying PCR technique-it took IBEA scientists just 14 days to build the 5,386nucleotide genome (Fig 2), which was also the first DNA completely sequenced by Frederick Sanger and co-workers in 1977. To demonstrate the accuracy of their accomplishment, beyond using DNA sequencing, the researchers showed that their synthetic viral construct was fully able to infect its natural host, E. coli. "Synthetic genomics will become commonplace and will provide the potential for a vastarray of new and complex chemistries altering our approaches to production of energy, pharmaceuticals, and 
textiles," Smith and his co-workers commented (Smith et al, 2003). At the press conference heralding the IBEA's results, Venter and US Secretary of Energy Spencer Abraham acknowledged the possibility of harmful misuse of this new technology, but were quick to reassure the public about the engagement of both the scientific and national security communities to tackle ethical and security concerns. Abraham also announced the creation of a special subcommittee of the Department's Biological and Environmental Research Advisory Committee to conduct a thorough review of IBEA's research and to recommend ways to accelerate it.

The synthesis of the complete genome of an infective bacteriophage from scratch raises a host of questions, but it is not a one-of-akind surprise. The chemical-biochemical synthesis of infectious poliovirus, the causal agent of poliomyelitis, from chemical building blocks based on the published genome sequence, was recently achieved by Eckard Wimmer and colleagues at the State U niversity of New York at Stony Brook, NY, USA (Cello et al, 2002). "The reason we did it was to prove that it can be done and it now is a reality," said Wimmer. "N ow people have to take it seriously. Progress in biomedical research has its benefits and it has its down side. There is a danger inherent to progress in sciences. This is a new reality, a new consideration."

Indeed, Wimmer hinted at the possibility that the same technique could be used to stitch together a more deadly scourge such as smallpox, or even a new super-pathogen. But this threat could be overcome if society is aware of it and can counteract it in a proper and timely way. "Any threat from bioterrorism will arise only if mass vaccination stops," Wimmer and co-workers wrote. "The potential for virus synthesis is an important factor for consideration in designing the closing strategies of the poliovirus eradication campaign" (Cello et al, 2002). In fact, some believe the menace of

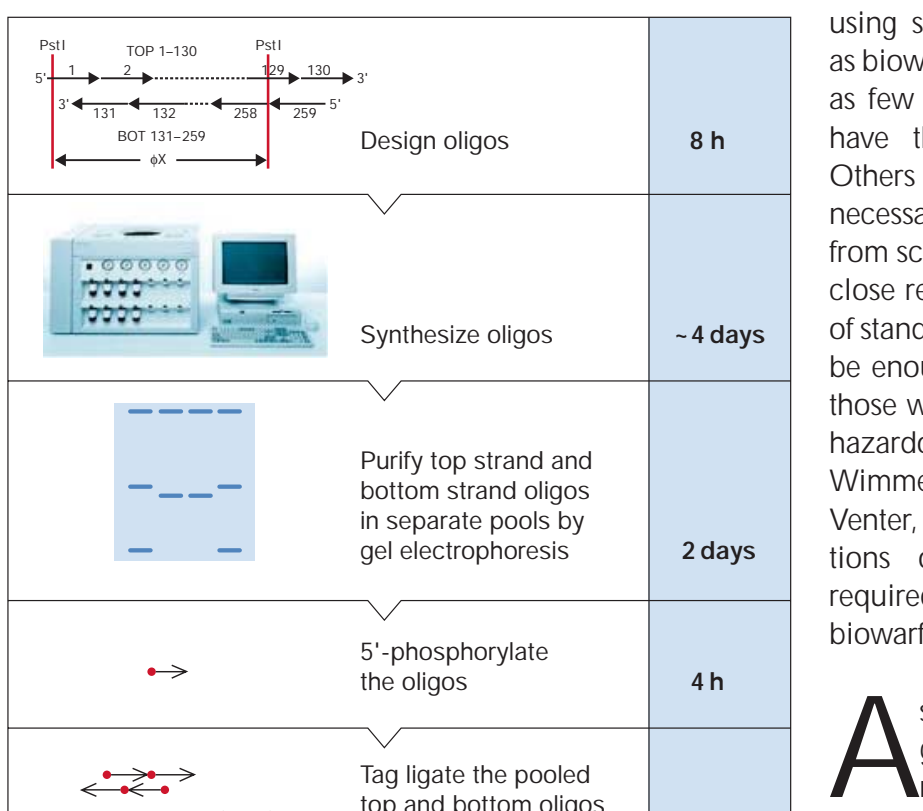

using synthetic pathogenic viruses as biow eapons is only a remote one, as few people in the world would have the skills to achieve this. 0 thers note, how ever, that it is not necessary to synthesize a genome from scratch to make smallpox, as a close relative and some knowledge of standard genetic engineering may be enough to hit the mark. Among those who criticized the potentially hazardous applications of the Wimmer group's research was Venter, who speculated that restrictions on publication might be required because of the organism's biowarfare potential.

A s discussion about minimal genome and synthetic life rolls on, so too does research. Estimates of the minimal proteinencoding gene set for the pathogenic bacterium Staphylococcus aureus (Ji et al, 2001) and for the classic bacterial model Bacillus subtilis (Kobayashi et al, 2003) have been released. While some criticize these achievements by arguing that there can be no single minimal genome because each environment requires a different minimal gene set, others strive to decide whether the frightening line of the "creation of life by man" has already been crossed. If the ability to replicate is an attribute of life, are viruses really living entities or simply chemicals? Maybe they are "chemical(s) with a life cycle", to use Wimmer's words.

Notwithstanding such basic debates, the prospects of designing new cell-based organisms with an expanded set of amino acids are real. If these advances can be used to answer central questions about basic biology, help the world to solve some of its environmental problems, provide improved tools to engineer useful plants and animals and treat lethal human diseases, it appears that relevant projects should be carried forward. What is noteworthy, however, is that the ethical and security risks associated with these initiatives are also clearly perceived, even by the main actors themselves- the research scientistswho in some cases underscored the 
lack of regulation and oversight governing such work. At a time when advances in chemistry and biochemistry are opening up new possibilities thanks to the expansion of the genetic code, another form of common code seems necessary: A code of conduct arising from the crosstalk between scientists, national and international authorities, backed by a broad engagement of citizens on the potential benefits and pitfalls of these developments.

\section{REFEREN CES}

Cello J, Paul AV, Wimmer E (2002) Chemical synthesis of poliovirus CDNA: generation of infectious virus in the absence of natural template. Science 297: 1016-1018

Chin JW, Cropp TA, Anderson JC, M ukherji M, Zhang Z, Schultz PG (2003) An expanded eukaryotic genetic code. Science 301: 964-967

Cho M K, Magnus D, Caplan AL, M cG ee D (1999) Ethical considerations in synthesizing a minimal genome. Science 286: 2087-2090

H ohsaka T, Sisido M (2002) Incorporation of nonnatural amino acids into proteins. Curr O pin Chem Biol 6: 809-815

Hutchinson CA III, Peterson SN, Gill SR, Cline RT, White O, Fraser CM, Smith HO, Venter JC (1999) G lobal transposon mutagenesis and a minimal M ycoplasma genome. Science 286: 2165-2169

JiY, Zhang B, Van H orn SF, Warren P, Woodnutt G, Burnham M KR, Rosenberg M (2001) Identification of critical staphylococcal genes using conditional phenotypes generated by antisense RNA. Science 293: 2266-2269

Kobayashi K et al (2003) Essential Bacillus subtilis genes. Proc N atl Acad Sci USA 100: 4678-4683

M ehl RA, Anderson JC, Santoro SW, Wang L, Martin AB, King DS, H orn DM , Schultz PG (2003) Generation of a bacterium with a 21 amino acid genetic code. J Am Chem Soc 125: 935-939

N oren CJ, Anthony-Cahill SJ, Griffith MC, Schultz PG (1989) A general method for site-specific incorporation of unnatural amino acids into proteins. Science 244: 182-188

Smith HO, Hutchinson CA III, Pfannkoch C, Venter JC (2003) G enerating a synthetic genome by whole genome assembly: $\phi X 174$ bacteriophage from synthetic oligonucleotides. Proc N atl Acad Sci USA 100: 15440-15445

Wang $L$ (2003) Expanding the genetic code. Science 302: 584-585

Wang L, Schultz PG (2002) Expanding the genetic code. Chem Commun 7: 1-11

Wang L, Brock A, Herberich B, Schultz PG (2001) Expanding the genetic code of Escherichia coli. Science 292: 498-500

Wang L, Zhang Z, Brock A, Schultz PG (2003a) Addition of the keto functional group to the genetic code of Escherichia coli. Proc N atl Acad Sci USA 100: 56-61

Wang L, Xie J, Deniz AA, Schultz PG (2003b) U nnatural amino acid mutagenesis of green fluorescent protein. J O rg Chem 68: 174-176

\section{Andrea Rinaldi}

doi:10.1038/sj.embor.7400131

\section{Push for innovation}

\author{
The fate of basic research in Europe has arrived on the radar screen \\ of politicians
}

\section{T} he large investments of time and effort seem to be paying off. After nearly two years of lobbying, meetings and position papers, the scientific community in Europe is on the verge of achieving a major goal: convincing the political powers of the need to establish a European Research Council (ERC). Largely thanks to the ERC Expert Group, set up in 2002 by the Danish Minister for Science and Technology to explore options for the creation of an ERC, politicians finally seem to be warming to this idea. "Scientific organizations have achieved a change in the political scene in research funding," José Mariano Gago (Fig 1), President of the Laboratory for Experimental Particle Physics and Instrumentation in Lisbon, Portugal, and Portugal's former Minister of Science and Technology, said at a meeting in Brussels in late February, organized by the Initiative for Science in Europe (ISE) group. "[The scientists'] demands are accepted, at least in words, by policy makers," he added.

\section{... the EC and other political bodies now openly concede that Europe is increasingly losing out in the global market of science and technology}

In a number of recent documents published by the European Commission (EC), several countries' leaders and ministers for science and research have reiterated the growing importance of basic research for the future economic and social well-being of Europe. More importantly, the EC and other political bodies now openly concede that Europe is increasingly losing out in the global market of science and technology, particularly in comparison with the USA. Indeed, the major demands of the scientific community have now finally arrived on the radar screen of politicians: first and foremost is the need to establish an ERC with additional money from the EU's budget to fund basic research at the European level. What started as a small group of mainly life scientists pushing for change has grown into a larger

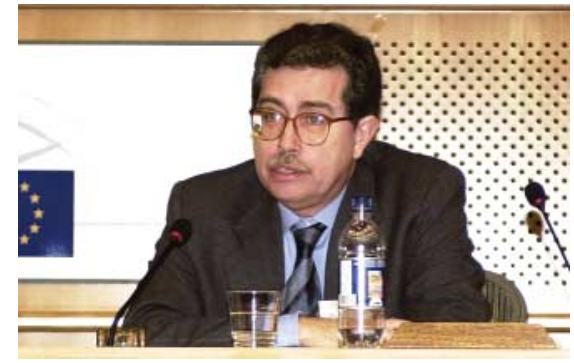

Fig1|JoséM ariano Gago: “Wemust go out and campaign for scientific debates not only at the European level but also in our own countries."

movement across all sciences and countries. This was further highlighted by an open letter, signed by 45 Nobel Laureates from Europe, to the European Commissioner for Research Philippe Busquin in support of the creation of an ERC.

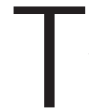
he main reason for a European fund for basic research is the fragmentation of science policy across the European landscape-as more than $90 \%$ of research funding is distributed by national research councils and funds, both competition and cooperation at an international level are impeded. "We have a fragmentation of efforts with dispersion of funding which often results in sub-optimal funding," said Pierre Papon from the École Supérieure de Physique et Chimie in Paris, France. Furthermore, Europe as a whole invests less in research and development in terms of a percentage of its gross domestic product compared with the USA (Gannon, 2003). "Europe needs more scientists but public funding per researcher is about half that of the USA," Gago said, which translates into lower salaries, bleaker career prospects and further contributes to the 'brain drain' of European scientists to the USA. And although some of the richer EU countries are doing fairly well, "in some countries the idea of science for the public good is absent," he noted. This has repercussions for Europe's scientific productivity, particularly when measured in terms of $\mathrm{Nobel}$ Prizes and the publication of highly cited 